\title{
The Synthesis and Light Absorption Behaviour of Novel Coumarin Chromophores
}

\author{
Kyoung Lyong An, Seung Rim Shin, Kun Jun, and Soo Youl Park* \\ Interface Chemistry \& Engineering Research Team, Korea Research Institute of Chemical Technology, \\ P.O. Box107, Yuseong, Daejeon 305-600, Korea. "E-mail: sypark@krict.re.kr
}

(Received October 15, 2013; Accepted April 1, 2014)

\begin{abstract}
The synthetic route to coumarin systems is well established and one approach of particular interest leads to the intermediate 7-diethylamino-3-formylcoumarin. A combination of the $N, N$-diethylamino-coumarin donor with a wide range of acceptor groups of varying electron withdrawing strength should permit the synthesis of a series of extended coumarin dyes with absorption maxima range from 500 to $600 \mathrm{~nm}$, or even beyond. In this communication, a novel efficient synthesis of indoles, benzothiazole and benzoxazole based on coumarin chromophores were achieved and the coloristic and fluorophoric properties of these chromophores were studied.
\end{abstract}

Key words: Coumarin, Knoevenagel condensation, Fluorescence, Chromophores

\section{INTRODUCTION}

The synthetic coumarins are a colorless compound with intense fluorescence. Such coumarins have been reported to be useful in fluorescence probes, sensors, switches, solar collection and lasers. ${ }^{1-10}$ The reasons for their wide range of applications are their spectral properties, mainly the intense fluorescence observed for many derivatives with appropriate substitution. For examples, the coumarins containing benzoxazolyl, benzothiazolyl and benzimidazolyl systems were reported in 1958. ${ }^{11}$ The influence of environmental effects on the photophysics of substituted coumarins has been extensively studied with steady state and time resolved spectroscopy. ${ }^{12-16}$ Therefore, the coumarin derivatives are widely used for monitoring the polarity and micro-viscosity of the environment in various simple, mixed or ionic solvents. Especially, it is worthy to note that, although hybrid coumarin-cyanine dyes have been broadly, used in fluorescent labeling, fluorescent imaging. ${ }^{17-21}$

\section{EXPERIMENTAL}

All reagent and solvents were of chemical pure grade, purchased from Aldrich or Junsei and were used without further purification. UV/Vis spectra were determined on a Perkin-Elmer Lambda 15 spectrophotometer. The fluorescence was measured on a Luminescence Spectrometer (LS-50). ${ }^{1} \mathrm{H}$ NMR spectra were recorded on a Bruker AMX $300 \mathrm{MHz}$ FT-NMR spectrometer. Mass spectrometric analyses were performed by a JNSDX 303 Mass spectrometer. Elemental analysis was performed on a PE-4000 instru- ment. All synthetic reactions were monitored by thin layer chromatography. Melting points were determined on an Electro-thermal IA 900.

\section{Synthesis of 7-diethylamino-3-formylcoumarin}

4-Diethylaminosalicyaldehyde $17.92 \mathrm{~g}$ (93 mmole), diethylmalonate $16.33 \mathrm{~g}(10.2 \mathrm{mmole})$ and piperidine $(20 \mathrm{ml})$ were stirred at $40{ }^{\circ} \mathrm{C}$ for 12 hours. To this mixture hydrochloric acid (18\%) $94 \mathrm{ml}$ was then added. The reaction mixture was stirred under reflux for 5 hours. On cooling the reaction mixture sodium acetate solution $14 \mathrm{ml}$ was added and the $\mathrm{pH}$ carefully adjusted to $\mathrm{pH} 4-5$ with aqueous sodium hydroxide solution (45\%). The resultant precipitate was filtered off, washed with water, and dried in an oven at $50{ }^{\circ} \mathrm{C}$ to give 7-diethylaminocoumarin $17.2 \mathrm{~g}$ (77.7\%). Dimethylformamide $7.14 \mathrm{~g}$ (98 mmole) was added dropwise to phosphorous oxychloride $16 \mathrm{~g}(104 \mathrm{mmole})$ at $40^{\circ} \mathrm{C}$. The mixture was then stirred at $50^{\circ} \mathrm{C}$ for 45 minutes with exclusion of moisture. To this was added a suspension of the 7-diethylaminocoumarin $15 \mathrm{~g}(70 \mathrm{mmole})$ in $N, N$-dimethylformamide $18 \mathrm{~g}$. The reaction mixture was heated to $60^{\circ} \mathrm{C}$ and stirred for 2 hours. The orange colored reaction mixture was then poured into ice $150 \mathrm{~g}$ and stirred for a further 2 hours. The solid was filtered off, washed with water and dried in an oven at $50{ }^{\circ} \mathrm{C}$, giving 7-diethylamino-3-formylcoumarin $9.6 \mathrm{~g}(56 \%)$. mp: 259-265 ${ }^{\circ} \mathrm{C}$. Mass spectrum (EI): found $\mathrm{M}=245$ (excepted) required for $\mathrm{M}=245$. Anal. Calcd for $\mathrm{C}_{14} \mathrm{H}_{15} \mathrm{NO}_{3}: \mathrm{C}, 68.56 ; \mathrm{H}$, $6.16 ; \mathrm{N}, 5.71 \%$. Found: $\mathrm{C}, 67.54 ; \mathrm{H}, 5.91 ; \mathrm{N}, 5.42 \%$. ${ }^{1} \mathrm{H}$ NMR (300 MHz, $\left.\mathrm{CDCl}_{3}\right): \delta(\mathrm{ppm}) 1.23(\mathrm{t}, 6 \mathrm{H}, \mathrm{J}=7.0 \mathrm{~Hz}$ ), 3.45 $(\mathrm{dd}, 4 \mathrm{H}, \mathrm{J}=7.0 \mathrm{~Hz}), 6.45(\mathrm{~d}, 1 \mathrm{H}, \mathrm{J}=2.5 \mathrm{~Hz}), 6.60(\mathrm{dd}, 1 \mathrm{H}, \mathrm{J}=$ $7.2 .5 \mathrm{~Hz}), 7.38(\mathrm{~d}, 1 \mathrm{H}, \mathrm{J}=4.5 \mathrm{~Hz}), 8.22(\mathrm{~s}, 1 \mathrm{H}), 10.09(\mathrm{~s}, 1 \mathrm{H})$. 
Synthesis of 2-(2-(7-(diethylamino)-2-0xo-2H-chromen-3yl)vinyl)-1-ethyl-3,3-dimethyl-3H-indol-1-ium iodide (No.1)

A mixture of 1-ethyl-3,3'-dimethylindolium iodide $18.9 \mathrm{~g}$ (60 mmole) and 7-diethylamino-3-formylcoumarin $12.25 \mathrm{~g}$ (50 mmole) in absolute ethanol and catalytic amount of piperidine $(2 \mathrm{ml})$ were stirred at room temperature. The reaction mixture was stirred under reflux for 5 hours. The precipitated solid was filtered, washed with ethanol, dried and recrystallized from benzene to yield $22.5 \mathrm{~g}(83 \%)$ as crystalline solid, mp: $259-265^{\circ} \mathrm{C}$. Mass spectrum (EI): found $\mathrm{M}=542$ (excepted) required for $\mathrm{M}=542$. Anal. Calcd for $\mathrm{C}_{27} \mathrm{H}_{31} \mathrm{IN}_{2} \mathrm{O}_{2}$ : $\mathrm{C}, 59.78 ; \mathrm{H}, 5.76 ; \mathrm{N}, 5.16 \%$. Found: $\mathrm{C}$, 59.99; H, 6.00; N, 4.98\%. ${ }^{1} \mathrm{H}$ NMR (300 MHz, $\left.\mathrm{CDCl}_{3}\right)$ : $\delta$ (ppm) $1.29(\mathrm{t}, 6 \mathrm{H}, \mathrm{J}=7.10 \mathrm{~Hz}), 1.62(\mathrm{t}, 3 \mathrm{H}, \mathrm{J}=7.24 \mathrm{~Hz}), 1.84$ (s, 6H), 3.52 (quart, $4 \mathrm{H}, \mathrm{J}=7.16 \mathrm{~Hz}$ ), 4.86 (quart, $2 \mathrm{H}, \mathrm{J}=$ $7.27 \mathrm{~Hz}), 6.46(\mathrm{~d}, 1 \mathrm{H}, \mathrm{J}=2.31 \mathrm{~Hz}), 6.70(\mathrm{dd}, 1 \mathrm{H}, \mathrm{J}=9.15$ $\mathrm{Hz}, \mathrm{J}=2.4 \mathrm{~Hz}), 7.43(\mathrm{dd}, 1 \mathrm{H}, \mathrm{J}=6.78 \mathrm{~Hz}, \mathrm{~J}=1.53 \mathrm{~Hz}$ ), 7.49 (multi, 3H), 8.00 (d, $1 \mathrm{H}, \mathrm{J}=15.9 \mathrm{~Hz}), 8.21(\mathrm{~d}, 1 \mathrm{H}, \mathrm{J}=$ $9.12 \mathrm{~Hz}), 8.60(\mathrm{~d}, 1 \mathrm{H}, \mathrm{J}=15.9 \mathrm{~Hz}), 10.19(\mathrm{~s}, 1 \mathrm{H})$

Synthesis of 2-(2-(7-(diethylamino)-2-oxo-2H-chromen3-yl)vinyl)-1-propyl-3,3-dimethyl-3H-indol-1-ium iodide (No.2)

A mixture of 1-propyl-3,3'-dimethylindolium iodide $19.74 \mathrm{~g}$ (60 mmole) and 7-diethylamino-3-formylcoumarin $12.25 \mathrm{~g}$ (50 mmole) in absolute ethanol and catalytic amount of piperidine $(2 \mathrm{ml})$ were stirred at room temperature. The reaction mixture was stirred under reflux for 5 hours. The precipitated solid was filtered, washed with ethanol, dried and recrystallized from benzene to yield $20.58 \mathrm{~g}(74 \%)$ as crystalline solid, $\mathrm{mp}: 258-263{ }^{\circ} \mathrm{C}$. Mass spectrum (EI): found $\mathrm{M}=556$ (excepted) required for $\mathrm{M}=556$, Anal. Calcd for $\mathrm{C}_{28} \mathrm{H}_{33} \mathrm{IN}_{2} \mathrm{O}_{2}$ : C, 60.43; H, 5.98; N, 5.03\%. Found: C, 60.79; $\mathrm{H}, 6.20 ; \mathrm{N}, 4.91 \% .{ }^{1} \mathrm{H}$ NMR $\left(300 \mathrm{MHz}, \mathrm{CDCl}_{3}\right): \delta$ (ppm) $1.16(\mathrm{t}, 3 \mathrm{H}, \mathrm{J}=7.34 \mathrm{~Hz}), 1.28(\mathrm{t}, 6 \mathrm{H}, \mathrm{J}=7.03 \mathrm{~Hz})$, 1.87 (s, $6 \mathrm{H}$ ), 2.05 (multi, 2H), 3.52 (quart, $4 \mathrm{H}, \mathrm{J}=7.16 \mathrm{~Hz}$ ), $4.77(\mathrm{t}, 2 \mathrm{H}, \mathrm{J}=6.87 \mathrm{~Hz}), 6.45(\mathrm{~d}, 1 \mathrm{H}, \mathrm{J}=2.01 \mathrm{~Hz}), 6.69$ (dd, $1 \mathrm{H}, \mathrm{J}=9.00 \mathrm{~Hz}, \mathrm{~J}=2.22 \mathrm{~Hz}$ ), 7.49 (multi, 4H), 8.05 $(\mathrm{d}, 1 \mathrm{H}, \mathrm{J}=15.8 \mathrm{~Hz}), 8.17(\mathrm{~d}, 1 \mathrm{H}, \mathrm{J}=9.12 \mathrm{~Hz}), 8.61(\mathrm{~d}, 1 \mathrm{H}$, $\mathrm{J}=15.9 \mathrm{~Hz}), 10.14(\mathrm{~s}, 1 \mathrm{H})$.

Synthesis of 2-(2-(7-(diethylamino)-2-oxo-2H-chromen3-yl)vinyl)-1-butyl-3,3-dimethyl-3H-indol-1-ium iodide (No.3)

A mixture of 1-butyl-3,3'-dimethylindolium iodide $20.58 \mathrm{~g}$ (60 mmole) and 7-diethylamino-3-formylcoumarin $12.25 \mathrm{~g}$ (50 mmole) in absolute ethanol and catalytic amount of piperidine $(2 \mathrm{ml})$ were stirred at room temperature. The reaction mixture was stirred under reflux for 5 hours. The precipitated solid was filtered, washed with ethanol, dried and recrystallized from benzene to yield $22.25 \mathrm{~g}(78 \%)$ as crystalline solid, mp: $260-263{ }^{\circ} \mathrm{C}$. Mass spectrum (EI): found $\mathrm{M}=571$ (excepted) required for $\mathrm{M}=571$ Anal. Calcd for $\mathrm{C}_{29} \mathrm{H}_{35} \mathrm{IN}_{2} \mathrm{O}_{2}$ : C, 61.05; H, 6.18; N, 4.91\%. Found: C, 61.23; $\mathrm{H}, 6.19 ; \mathrm{N}, 5.01 \% .{ }^{1} \mathrm{H}$ NMR (300 MHz, $\left.\mathrm{CDCl}_{3}\right): \delta(\mathrm{ppm})$ $1.01(\mathrm{t}, 3 \mathrm{H}, \mathrm{J}=7.27 \mathrm{~Hz}$ ), $1.28(\mathrm{t}, 6 \mathrm{H}, \mathrm{J}=7.10 \mathrm{~Hz}$ ), 1.61 (multi, $2 \mathrm{H}$ ), 1.87 (s, 6H), 1.96 (multi, 2H), 3.52 (quart, 4H, J = $7.14 \mathrm{~Hz}), 4.77(\mathrm{t}, 2 \mathrm{H}), 6.45(\mathrm{~d}, 1 \mathrm{H}, \mathrm{J}=2.31 \mathrm{~Hz}), 6.69(\mathrm{dd}$, $1 \mathrm{H}, \mathrm{J}=9.12 \mathrm{~Hz}, \mathrm{~J}=2.4 \mathrm{~Hz}$ ), 7.47 (multi, 4H), $8.05(\mathrm{~d}, 1 \mathrm{H}$, $\mathrm{J}=15.8 \mathrm{~Hz}), 8.17(\mathrm{~d}, 1 \mathrm{H}, \mathrm{J}=9.12 \mathrm{~Hz}), 8.62(\mathrm{~d}, 1 \mathrm{H}, \mathrm{J}=15.9 \mathrm{~Hz})$, $10.14(\mathrm{~s}, 1 \mathrm{H})$.

Synthesis of 2-(2-(7-(diethylamino)-2-oxo-2H-chromen3-yl)vinyl)-1-hexyl-3,3-dimethyl-3H-indol-1-ium iodide (No.4)

A mixture of 1-hexyl-3,3'-dimethylindolium iodide $22.26 \mathrm{~g}$ (60 mmole) and diethylamino-3-formylcoumarin $12.25 \mathrm{~g}$ (50 mmole) in absolute ethanol and catalytic amount of piperidine $(2 \mathrm{ml})$ were stirred at room temperature. The reaction mixture was stirred under reflux for 5 hours. The precipitated solid was filtered, washed with ethanol, dried and recrystallized from benzene to yield $24.24 \mathrm{~g} \mathrm{(81 \% )}$ as crystalline solid, mp: $145-155^{\circ} \mathrm{C}$. Mass spectrum (EI): found $\mathrm{M}=598$ (excepted) required for $\mathrm{M}=598$. Anal. Calcd for $\mathrm{C}_{31} \mathrm{H}_{39} \mathrm{IN}_{2} \mathrm{O}_{2}$ : C, 62.20; H, 6.57; N, 4.68\%. Found: C, $62.60 ; \mathrm{H}, 6.36 ; \mathrm{N}, 4.88 \% .{ }^{1} \mathrm{H}$ NMR $\left(300 \mathrm{MHz}, \mathrm{CDCl}_{3}\right): \delta$ (ppm) 0.87 (t, 3H, J = 7.06 Hz), 1.29 (multi, 10H), 1.56 (multi, $2 \mathrm{H}$ ), 1.88 (s, 6H), 1.97 (multi, $2 \mathrm{H}$ ), 3.52 (quart, $4 \mathrm{H}, \mathrm{J}=7.16 \mathrm{~Hz}$ ), $4.74(\mathrm{t}, 2 \mathrm{H}), 6.45(\mathrm{~d}, 1 \mathrm{H}, \mathrm{J}=2.31 \mathrm{~Hz}), 6.69(\mathrm{dd}, 1 \mathrm{H}, \mathrm{J}=9.12 \mathrm{~Hz}$, $\mathrm{J}=2.4 \mathrm{~Hz}$ ), 7.47 (multi, 4H), $8.04(\mathrm{~d}, 1 \mathrm{H}, \mathrm{J}=15.81 \mathrm{~Hz}), 8.14$ $(\mathrm{d}, 1 \mathrm{H}, \mathrm{J}=9.12 \mathrm{~Hz}), 8.62(\mathrm{~d}, 1 \mathrm{H}, \mathrm{J}=15.84 \mathrm{~Hz}), 10.13(\mathrm{~s}, 1 \mathrm{H})$.

Synthesis of 2-(2-(7-(diethylamino)-2-oxo-2H-chromen3-yl)vinyl)-3-ethylbenzo[d]thiazol-3-ium iodide (No.5)

A mixture of 3-ethylbenzothiazolium iodide $15.25 \mathrm{~g}(60$ mmole) and diethylamino-3-formylcoumarin $12.25 \mathrm{~g}$ (50 mmole) in absolute ethanol and catalytic amount of piperidine $(2 \mathrm{ml})$ were stirred at room temperature. The reaction mixture was stirred under reflux for 5 hours. The precipitated solid was filtered, washed with ethanol, dried and recrystallized from benzene to yield $22.36 \mathrm{~g}(84 \%)$ as crystalline solid, mp: $240-245^{\circ} \mathrm{C}$. Mass spectrum (EI): found $\mathrm{M}=406$ (excepted) required for $\mathrm{M}=532$. Anal. Calcd for $\mathrm{C}_{24} \mathrm{H}_{25} \mathrm{IN}_{2} \mathrm{O}_{2} \mathrm{~S}: \mathrm{C}, 54.14 ; \mathrm{H}, 4.73 ; \mathrm{N}, 5.26 \%$. Found: C, 51.49; $\mathrm{H}, 4.80 ; \mathrm{N}, 4.74 \% .{ }^{1} \mathrm{H} N M R(300 \mathrm{MHz}, \mathrm{DMSO} \mathrm{d} 6): \delta(\mathrm{ppm})$ $1.15(\mathrm{t}, 6 \mathrm{H}, \mathrm{J}=6.90 \mathrm{~Hz}), 1.47(\mathrm{t}, 3 \mathrm{H}, \mathrm{J}=7.09 \mathrm{~Hz}$ ), 3.52 (quart, $4 \mathrm{H}, \mathrm{J}=6.86 \mathrm{~Hz}$ ), 4.78 (quart, $2 \mathrm{H}, \mathrm{J}=7.19 \mathrm{~Hz}), 6.66(\mathrm{~d}, 1 \mathrm{H}, \mathrm{J}$ 
$=2.12 \mathrm{~Hz}), 6.86(\mathrm{dd}, 1 \mathrm{H}, \mathrm{J}=9.08 \mathrm{~Hz}, \mathrm{~J}=2.26 \mathrm{~Hz}), 7.57(\mathrm{~d}$, $1 \mathrm{H}, \mathrm{J}=9.10 \mathrm{~Hz}), 7.73(\mathrm{t}, 1 \mathrm{H}, \mathrm{J}=7.59 \mathrm{~Hz}), 7.83(\mathrm{t}, 1 \mathrm{H}, \mathrm{J}=7.25$ $\mathrm{Hz}), 8.02(\mathrm{~s}, 2 \mathrm{H}), 8.25(\mathrm{~d}, 1 \mathrm{H}, \mathrm{J}=8.34 \mathrm{~Hz}), 8.38(\mathrm{~d}, 1 \mathrm{H}, \mathrm{J}$ $=7.41 \mathrm{~Hz}), 8.63(\mathrm{~s}, 1 \mathrm{H})$.

Synthesis of 2-(2-(7-(diethylamino)-2-oxo-2H-chromen3-yl)vinyl)-3-propylbenzo[d]thiazol-3-ium iodide (No.6)

A mixture of 3-propylbenzothiazolium iodide $19.14 \mathrm{~g}$ (60 mmole) and diethylamino-3-formylcoumarin $12.25 \mathrm{~g}$ (50 mmole) in absolute ethanol and catalytic amount of piperidine $(2 \mathrm{ml})$ were stirred at room temperature. The reaction mixture was stirred under reflux for 5 hours. The precipitated solid was filtered, washed with ethanol, dried and recrystallized from benzene to yield $21.58 \mathrm{~g}$ (79\%) as crystalline solid, mp: $235-240{ }^{\circ} \mathrm{C}$. Mass spectrum (EI): found $\mathrm{M}=546$ (excepted) required for $\mathrm{M}=546$. Anal. Calcd for $\mathrm{C}_{25} \mathrm{H}_{27} \mathrm{IN}_{2} \mathrm{O}_{2} \mathrm{~S}$ : C, 54.95; H, 4.98; N, 5.13\%. Found: C, 52.67; H, 5.88; N, 4.97\%. ${ }^{1} \mathrm{H}$ NMR (300 MHz, $\left.\mathrm{CDCl}_{3}\right): \delta$ (ppm) $1.17(\mathrm{t}, 3 \mathrm{H}, \mathrm{J}=7.37 \mathrm{~Hz}), 1.27(\mathrm{t}, 6 \mathrm{H}, \mathrm{J}=7.14 \mathrm{~Hz}), 2.07$ (multi, $2 \mathrm{H}, \mathrm{J}=7.34 \mathrm{~Hz}$ ), 3.50 (quart, $4 \mathrm{H}, \mathrm{J}=7.15 \mathrm{~Hz}$ ), 4.89 (t, $2 \mathrm{H}, \mathrm{J}=7.26 \mathrm{~Hz}), 6.46(\mathrm{~d}, 1 \mathrm{H}, \mathrm{J}=2.31 \mathrm{~Hz}), 6.67(\mathrm{dd}, \mathrm{H}, \mathrm{J}=$ $9.07 \mathrm{~Hz}, \mathrm{~J}=2.42 \mathrm{~Hz}$ ), 7.64 (t, 1H, J = 6.87 Hz), 7.74 (multi, $2 \mathrm{H}), 7.87(\mathrm{~d}, 1 \mathrm{H}, \mathrm{J}=9.08 \mathrm{~Hz}), 8.15(\mathrm{~d}, 1 \mathrm{H}, \mathrm{J}=7.72 \mathrm{~Hz}), 8.34$ $(\mathrm{d}, 1 \mathrm{H}, \mathrm{J}=15.21 \mathrm{~Hz}), 8.53(\mathrm{~d}, 1 \mathrm{H}, \mathrm{J}=15.23 \mathrm{~Hz}), 9.54(\mathrm{~s}, 1 \mathrm{H})$.

Synthesis of 2-(2-(7-(diethylamino)-2-oxo-2H-chromen3-yl)vinyl)-3-hexylbenzo[d]oxazol-3-ium iodide (No.7)

A mixture of 1-hexyl-benzoxazole iodide $20.7 \mathrm{~g}$ (60 mmole) and diethylamino-3-formylcoumarin $12.25 \mathrm{~g}$ (50 mmole) in absolute ethanol and catalytic amount of piperidine $(2 \mathrm{ml})$ were stirred at room temperature. The reaction mixture was stirred under reflux for 5 hours. The precipitated solid was filtered, washed with ethanol, dried and recrystallized from benzene to yield $26 \mathrm{~g} \mathrm{(76 \% )} \mathrm{as} \mathrm{crystalline} \mathrm{solid,} \mathrm{mp:} \mathrm{124-}$ $128^{\circ} \mathrm{C}$. Mass spectrum(EI): found $\mathrm{M}=572$ (excepted) required for $\mathrm{M}=572$. Anal. Calcd for $\mathrm{C}_{28} \mathrm{H}_{33} \mathrm{IN}_{2} \mathrm{O}_{3}$ : C, 58.74; $\mathrm{H}, 5.81$; N, 4.89\%. Found: C, 58.21; H, 5.63; N, 4.71\%. ${ }^{1} \mathrm{H}$ NMR $\left(300 \mathrm{MHz}, \mathrm{CDCl}_{3}\right): \delta(\mathrm{ppm}) 0.87(\mathrm{t}, 3 \mathrm{H}, \mathrm{J}=6.93 \mathrm{~Hz}), 1.30$ (multi, 10H), 1.57 (multi, 2H), 2.03 (multi, $2 \mathrm{H}, \mathrm{J}=7.60 \mathrm{~Hz}$ ), 3.51 (quart, $4 \mathrm{H}, \mathrm{J}=7.13 \mathrm{~Hz}), 4.89(\mathrm{t}, 2 \mathrm{H}, \mathrm{J}=7.23 \mathrm{~Hz}), 6.45(\mathrm{~d}, 1 \mathrm{H}$, $\mathrm{J}=2.30 \mathrm{~Hz}), 6.68(\mathrm{dd}, 1 \mathrm{H}, \mathrm{J}=9.09 \mathrm{~Hz}, \mathrm{~J}=2.42 \mathrm{~Hz}), 7.66$ (multi, 3H), 7.82 (multi, 1H), $7.96(\mathrm{~d}, 1 \mathrm{H}, \mathrm{J}=9.09 \mathrm{~Hz}), 8.13$ $(\mathrm{d}, 1 \mathrm{H}, \mathrm{J}=15.37 \mathrm{~Hz}), 8.65(\mathrm{~d}, 1 \mathrm{H}, \mathrm{J}=15.40 \mathrm{~Hz}), 9.68(\mathrm{~s}, 1 \mathrm{H})$.

\section{RESULTS AND DISCUSSION}

\section{Synthesis of Coumarin Derivatives}

The general approach to 7-diethylamino-3-formylcoumarin and the derived coumarin dyes is summarized in

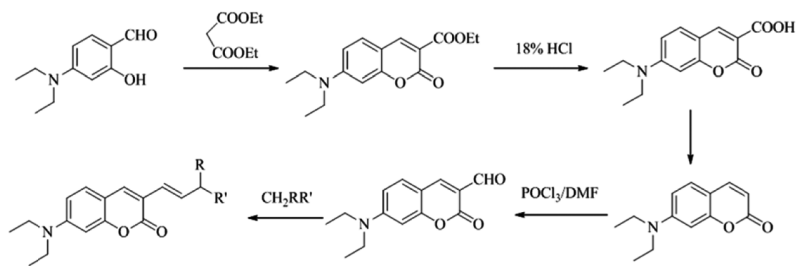

Scheme 1. The synthetic route of coumarin chromophores.

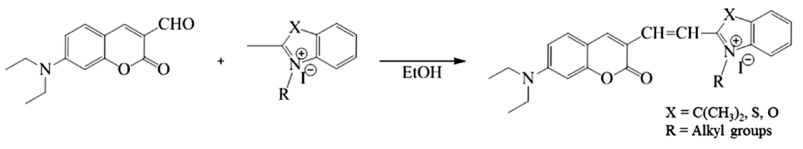

Scheme 2. The synthetic route of the new coumarin based chromophores.

Scheme 1. Reaction of 4-diethylaminosalicylaldehyde with diethylmalonate, under base catalyzed condition with piperidine gave 7-diethylaminocoumarin-3-carboxylic acid ethyl ester. The carboxylic ester could then be converted to 7diethylaminocoumarin by refluxing in $18 \%$ hydrochloric acid solution, the reaction proceeding via decarboxylation of carboxylic acid intermediate. Vilsmeier formylation of then gave 7-diethylamino-3-formylcoumarin. By condensation the coumarin aldehyde with a suitable active methylene compounds could be synthesized. The new extended coumarin dyes prepared by this general method are listed in Table 1.

Table 1. Physical characterization data of coumarine compounds

Mw (g/mol) $\mathrm{MP}\left({ }^{\circ} \mathrm{C}\right)$ Purity (\%)




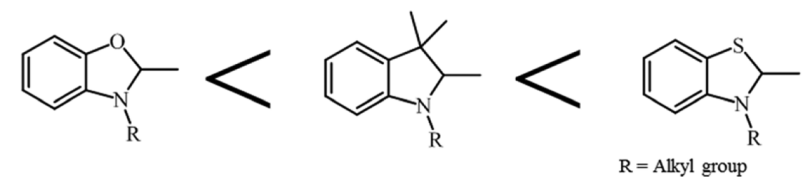

Figure 1. The nucleophilic effect of benzothiazole, indole and benzoxazole.

All compounds were confirmed by ${ }^{1} \mathrm{H}$ NMR, MS and EA.

Coumarin aldehydes were synthesized by the conventional Vilsmeier reaction. A complication was encountered in the reaction of 7-diethylamino-3-formylcoumarin with Fisher's base, which gave dye (Fig. 1). The reaction of equimolar quantities of the two species gave pale yellow compounds which slowly turned green with intense fluorescence in the visible region.

\section{Visible Absorption Spectra of Coumarin Derivatives}

The visible absorption spectra of the coumarin dyes were measured in dichloromethane, methanol and $N, N$ dimethylformamide, so giving and indication of solvatochromic behavior. The phenomenon of solvatochromism refers to the change in the ultraviolet, visible and fluorescence spectrum of a compound brought about a change in its surrounding medium, i.e. solvents. The spectral change can involve an alternation in the position, intensity and shape of absorption bands. The term "solvatochromism" was coined by Hantzsch in $1922 .{ }^{22}$ Molar extinction coefficients of pure compounds were measured in methanol. The results of the spectral evaluation are summarized in Table 2.

It is a general feature that when the electron acceptor strength is increased within a donor-acceptor system a bathochromic shift is observed. ${ }^{23-25}$ This is exemplified within the series of dyes. The bathochromic efficiency of this coumarin compounds is determined by the nucleophilicity of the activated methyl group, i.e. benzothiazole, indoline, benzoxazole. For example, the more electron donating strength(nucleophilicity) of the benzothiazole group in these dyes affords a useful bathochromic shift compared to the other active methyl groups i.e. indoline and benzoxazole (Fig. 1).

The chromophoric system is typical of coumarin chromophores in that it shows relatively solvatochromism. This can be attributed to the electronic symmetry of such systems and the low dipole moment in the ground and excited states. However this is due to the presence of strong intermolecular hydrogen bonding, which influences the color, i.e. absorbing wavelength and is solvent dependent.

For example, the coumarin chromophores based on indoles (No 1-4) have max (maxima of wavelength) = 600-601 nm in dichloromethane as non-polar solvent, and whereas the coumarin dyes absorbs max (maxima of wavelength) $=574-577 \mathrm{~nm}$ in methanol as polar solvent with slightly shorter wavelengths. The situation is the same that coumarin dyes containing benzothiazoles and benzoxazoles are absorption maxima in the range max (maxima of wavelength) $=563-581 \mathrm{~nm}$ and max (maxima of wavelength) $=534-546 \mathrm{~nm}$ in dichloromethane and methanol respectively. The results of the visible absorption spectra in various solvents were summarized in Table 2.

This is steric hindrance, leading to decreased molecular planarity and thus reduced $\pi, \pi$ overlap. Thus bathochromic shift in the series are smaller than expected. Positive solvatochromism (i.e, a bathochromic shift on going from a non-polar to polar solvent) is typical of most donoracceptor chromophores, and indicates that the excited state is more polar than the ground state. In the series of coumarin dyes, bathochromic shifts vary from about 24$35 \mathrm{~nm}$ between methanol and methylene chloride as solvents.

\section{Fluorescence Emission Spectra of Coumarin Derivatives}

In general, traditional fluorescent dyes have spectral properties in the the ultraviolet, visible region. Coumarin, Rhodamine and Phthalocyanine are common visible fluorophores. Fluorescent coumarins have the advantage over

Table 2. Light absorption and emission spectra data for coumarin compounds

\begin{tabular}{lcccccccccc}
\hline & $\begin{array}{c}\varepsilon_{\max }\left(\mathrm{Lmol}^{-1} \mathrm{~cm}^{-1}\right) \\
\text { in Methanol }\end{array}$ & \multicolumn{3}{c}{ Methanol } & \multicolumn{3}{c}{ DMF } & \multicolumn{3}{c}{ Dichloromethane } \\
\hline No. 1 & 60,240 & 574.5 & 658 & 83.5 & 579.5 & 663 & 83.5 & 600.5 & 669 & 68.5 \\
No.2 & 90,800 & 578.0 & 657 & 79 & 581.0 & 661.5 & 80.5 & 602.0 & 661.5 & 59.5 \\
No.3 & 83,920 & 578.0 & 656 & 78 & 581.0 & 661 & 80 & 602.0 & 656.5 & 54.5 \\
No.4 & 62,880 & 577.0 & 655 & 78 & 581.0 & 656 & 75 & 601.5 & 654.5 & 53 \\
No.5 & 18,623 & 546.5 & 645 & 98.5 & 553.5 & 655.5 & 102 & 581.0 & 644.5 & 63.5 \\
No.6 & 64,640 & 546.5 & 643 & 96.5 & 553.5 & 658 & 104.5 & 581.0 & 646 & 65 \\
No.7 & 70,080 & 534.0 & 609.5 & 75.5 & 538.0 & 627.5 & 89.5 & 563.0 & 610 & 47 \\
\hline
\end{tabular}


conventional colorimetric indicators of much greater detection sensitivity. Consequently, these have been much recent interest in these, particularly from the biochemical and medical diagnostics areas. The following our experimental result may be adopted to provide this information. The spectral properties of the coumarins synthesized such as absorption maxima max (maxima of wavelength), emission maxima max (maxima of wavelength) were measured in methanol, $N, N$-dimethylformamide and dichloromethane. The coumarin compounds, having the indoline substituents, showed absorption maxima in the range of $574-578 \mathrm{~nm}$ in methanol. In $N, N$-dimethylformamide and dichloromethane, they displayed absorption maxima in the range of 579-581 $\mathrm{nm}$ and 600-602 nm, respectively. The coumarin based on benzothiazole typed showed absorption maxima at $546 \mathrm{~nm}$ in methanol compared to the absorption maxima at 553 and $581 \mathrm{~nm}$ in $\mathrm{N}, \mathrm{N}$-dimethylformamide and dichloromethane, respectively. Finally, the coumarin, having the benzoxazole, showed absorption maxima at $534 \mathrm{~nm}, 538 \mathrm{~nm}$ and $563 \mathrm{~nm}$ in methanol, $\mathrm{N}, \mathrm{N}$-dimethylformamide and dichloromethane, respectively. The indoline typed compounds displayed similar fluorescence spectra in the range of 600-658 nm and benzothiazoles showed in the range of $581-655 \mathrm{~nm}$ in a various solvents. In case of benzoxazole typed coumarin showed in the range of 538-609 $\mathrm{nm}$. The coumarin compounds exhibited large Stokes shift of $98 \mathrm{~nm}$ and lowest Stokes shift of $53 \mathrm{~nm}$. Thus fluorescence spectra were measured in dichloromethane, methanol and $N, N$ dimethylformamide. The fluorescence data for dyes are summarized in Table 2.

To investigate the influence of solvents, their visible
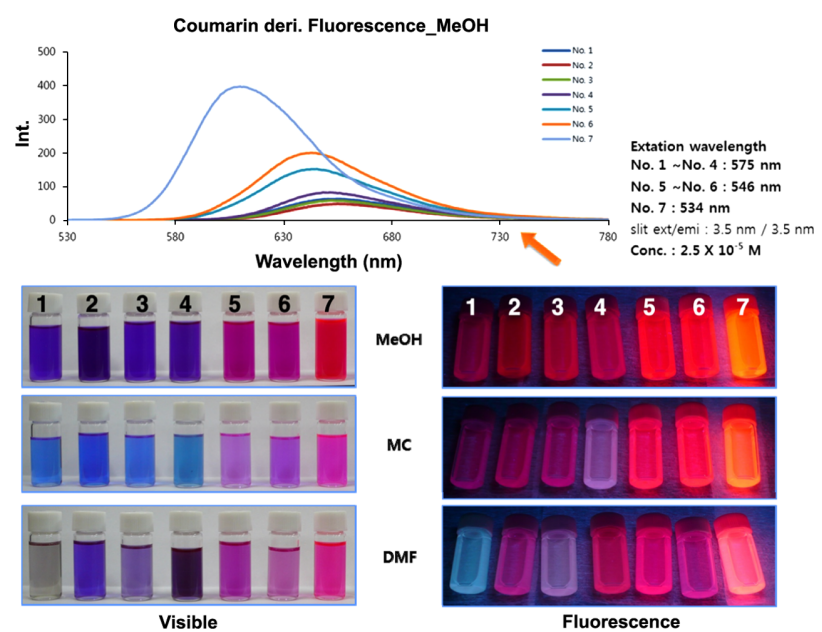

Figure 2. The fluorescence spectra of $2.5 \times 10^{-5} \mathrm{M}$ concentration in organic solution with an excitation at $575 \mathrm{~nm}, 546 \mathrm{~nm}$ and $534 \mathrm{~nm}$ respectively. absorption and fluorescence spectra were measured in a series of different solvent such as methanol, dichloromethane and $N, N$-dimethylformamide. Although the bathochromic shift induced by solvatochromism is not large, the visual color change is very obvious for these dyes. For example, these dyes showed the color change in the range of 540-730 nm and the color changes to a more intense bright with almost fluorescent. The color change can be attributed extinction coefficients. The color change phenomenon is shown in Fig. 2.

\section{CONCLUSION}

The synthetic route to coumarin systems is well established and one approach of particular interest leads to the intermediate 7-diethylamino-3-formylcoumarin. Knoevenagel type condensation of this aldehyde with active methylene compounds can lead to a coumarin systems with extended conjugation. A combination of the $N, N$-diethylamino-coumarin donor with a wide range of acceptor groups of varying electron withdrawing strength should permit the synthesis of a series of extended coumarin dyes with absorption maxima range from 500 to $600 \mathrm{~nm}$, or even beyond. It was of interest to examine the fluorescence properties of the new coumarin dyes synthesized, as they could have technical value as long wavelength fluorophore. Also, it must be noted that the coumarin compounds did show dramatic color changes in solvent polarity and ability to form H-bond.

\section{REFERENCES}

1. Prasanna de Silva, A.; Gunaratante, H. Q. N.; Gunnlaugsson, Th.; Huxley, A. J. M.; Mc Coy, C. P.; Rademacher, J. T.; Rice, T. E. Signaling Recognition Events with Fluorescent Sensors and Switches. Chem. Rev. 1997, 97, 1515-1566.

2. Prasanna de Silva, A.; Vance, T. P.; West, M. E. S.; Wright, G. D. Bright Molecules with Sense, Logic, Numeracy and Utility. Org. Biomol. Chem. 2008, 6, 2468-2481.

3. Ohkawa, M.; Ishii, K. U.S. Patent 3,933,847, 1976.

4. Horst, H. U.S. Patent 3,985,763, 1976.

5. Loew, P.; Schwander, H.; Kristinsson, H. U.S. Patent 4,064,136, 1977.

6. Loew, P. U.S. Patent 4,146,712, 1979.

7. Ayyangar, N. R.; Srinivasan, K. V.; Daniel, T. Polycyclic Compounds Part VI: Structural Features of C.I. Disperse Yellow 232. Dyes and Pigments 1990, 13(4), 301-310.

8. Ayyangar, N. R.; Snnivasan, K. V.; Daniel, T. Polycyclic Compounds Part VII: Synthesis, Laser Characteristics and Dyeing Behaviour of 7-Diethylamno-2H-1-benzopyran-2-ones. Dyes and Pigments 1991, 16(3), 197-204.

9. Moeckli, P. Preparation of Some New Red Fluorescent 4- 
Cyanocoumarin Dyes. Dyes and Pigments 1980, 1(1), 3-15.

10. Mockli, P. U.S. Patent 4,609,738, 1986; U.S. Patent 5,547,579, 1985.

11. Mach, W.; Augart, D.; Scheuermann, H. Ger. Offen. 2,253,538, 1972.

12. Horng, M. L.; Gardeski, J. A.; Papazyan, A.; Maroncelli, M. Subpicosecond Measurement of Polar Salvation Dynamics: Coumarin 153 Revisited. J. Phys. Chem. 1995, 99, 1731117337.

13. Arbeloa, T. L.; Arbeloa, F. L.; Arbeloa, I. L. Influence of Fluorinated Group on the Photophysics of 7-Aminocoumarins. J. Luminescence 1996, 68, 149-155.

14. Du, D. M.; Wang, Y. M.; Meng, J. B. Micro-environmental Effects on the Photochemical and Photophysical Processes of Long Chain Coumarin Esters. Chem. J. Chin. Univ.-Chin. 1998, 19, 1611-1613.

15. Raju, B. B.; Costa, S. M. B. Photophysical Properties of 7-Diethylaminocoumarin Dyes in Dioxanewater Mixtures: Hydrogen Bonding, Dielectric Enrichment and Polarity Effects. Phys. Chem. Chem. Phys. 1999, 1, 3539-3547.

16. Ramalingam, A.; Sivaram. B. M.; Palamisamy, P. K.; Masilamani, V. Photophysics of TICT States of 7-Diethylamino-4methyl Coumarin Dye by Energy Transfer Techniques. Spectrochim. Acta, Part A: Molec. Biomolec. Spect. 2000, 56, 1205-1210.

17. Mandal, P. K.; Paul, A.; Samanta, A. Fluorescence Studies of Environmentally Benign Solvents: Solvation Dynamics of
Coumarin 102 in [BMIM][BF4]. Res. Chem. Intermed. 2005, 31, 575-583.

18. Raikar, U. S.; Renuka, C. G.; Nadaf, Y. F.; Mulimani, B. G; Karguppikar, A. M. Rotational Diffusion and Solvatochromic Correlation of Coumarin 6 Laser Dye. J. Fluorescence 2006, 16, 847-854.

19. Raikar, U. S.; Renuka, C. G.; Nadaf, Y. F.; Mulimanim B. G.; Karguppikar, A. M.; Soudagar, M. K. Solvent Effects on the Absorption and Fluorescence Spectra of Coumarins 6 and 7 Molecules: Determination of Ground State and Excited State Dipole Moment. Spectrochim. Acta. 2006, Part A 65, 673-677.

20. Tablet, C.; Hildebrand, M. Quenching of the Fluorescence of Carboxy-5,6-benzocoumarin by Aromatic Amines. J. Photochem. Photobiol. A Chem. 2007, 189, 73-79.

21. Wang, T.; Zhao, Y.; Shi, M.; Wu, F. The Synthesis of Novel Coumarin Dyes and the Study of Their Photoreaction Properties. Dyes Pigments 2007, 75, 104-110.

22. Hantzsch, A. Ber. Dtsch, Chem. Ges, 1922, 55, 953.

23. Pugzlys, A.; Hania, P. R.; Augulis, R.; Duppen, S. K.; Van Loosdrecht, P. H. M. Int. J. Photoenergy 2006, 2429.

24. Camposeo, A.; Persano, L.; Del Carro, P.; Cirgili, T.; Cingolani, R.; Pisignano, D. Org. Electro 2007, 8, 114-119.

25. Ricceri, R.; Abbotto, A.; Facchetti, A.; Pagani, G. A.; Gabrielli, G. Langmuir 1997, 13, 3434-3441. 